Eye (1990) 4, 526-530

\title{
Penetration of Synthetic Corticosteroids into Human Aqueous Humour
}

\author{
C. N. J. McGHEE ${ }^{1,3}$ D. G. WATSON ${ }^{3}$ J. M. MIDGLEY, ${ }^{3}$ M. J. NOBLE, ${ }^{2}$ \\ G. N. DUTTON, ${ }^{2}$ A. I. FERN ${ }^{1}$ \\ Glasgow
}

\begin{abstract}
Summary
The penetration of prednisolone acetate $(1 \%)$ and fluorometholone alcohol $(0.1 \%)$ into human aqueous humour following topical application was determined using the very sensitive and specific technique of Gas Chromatography with Mass Spectrometry (GCMS). Prednisolone acetate afforded peak mean concentrations of $669.9 \mathrm{ng} / \mathrm{ml}$ within two hours and levels of $28.6 \mathrm{ng} / \mathrm{ml}$ in aqueous humour were detected almost 24 hours post application. The peak aqueous humour level of fluorometholone was $5.1 \mathrm{ng} / \mathrm{ml}$. The results are compared and contrasted with the absorption of dexamethasone alcohol $(0.1 \%)$, betamethasone sodium phosphate $(0.1 \%)$ and prednisolone sodium phosphate $(0.5 \%)$ into human aqueous humour.
\end{abstract}

Topical corticosteroid preparations have been used widely in ophthalmology since the early 1960s and over the last 10 years the choice of preparations has become larger and more varied. Unfortunately, data on the intraocular penetration of these steroids in humans has not paralleled the expansion in the number of available preparations; indeed until recently, estimation of intraocular penetration has been reliant upon extrapolation of data from animal models (see Watson et al., 1988, for bibliography). The authors have previously reported the pharmacokinetic profiles of commercial preparations of dexamethasone alcohol $(0.1 \%),{ }^{1}$ prednisolone sodium phosphate $(0.5 \%)^{2}$ and betamethasone sodium phosphate $(0.1 \%)^{3}$ in human aqueous humour using the highly sensitive and specific technique of gas chromatography with mass spectrometry (GCMS). ${ }^{4,5}$ This communication presents our data on the penetration of prednisolone acetate $(1.0 \%)$ and fluoromethalone alcohol $(0.1 \%)$ (preliminary results) into the aqueous humour of patients undergoing elective cataract surgery.

\section{Subjects and Methods}

Patients who were scheduled to undergo routine cataract surgery were recruited to the study and informed consent was obtained in all cases $(n=88)$. Patients with corneal disease or inflammatory ocular conditions which might have affected the penetration of the steroid into the eye were excluded from the study. None of the patients had been prescribed topical or systemic steroids in the six months prior to surgery. Sixty-six eyes of 66 patients were included in the prednisolone acetate group (group 1) (mean age 77 years, range 59-95 years). Twenty-two eyes of 22 patients were included in the fluorometholone group (group 2) (mean age 73 years,

From: ${ }^{1}$ Department of Ophthalmology, Southern General Hospital, Govan Road, Glasgow G51 4TF. ${ }^{2}$ Tennent Institute of Ophthalmology, University of Glasgow, Western Infirmary, Glasgow G11 6NT. ${ }^{3}$ Department of Pharmacy, Division of Pharmaceutical Chemistry, University of Strathclyde, Glasgow G1 1XW.

Correspondence to: Dr. C. N. J. McGhee, Tennent Institute of Ophthalmology, Western Infirmary, Glasgow G11 6NT. 
range 50-94 years). Fifty-one of the patients in group 1 and twelve in group 2 had surgery performed under general anaesthesia. The remaining patients in both groups received retrobulbar anaesthesia.

Fifty microlitres of prednisolone acetate 1\% (Predforte: Allergen UK Ltd.) were introduced by micropipette into the lower conjunctival fornix of the eye being prepared for surgery at varied time intervals up to 24 hours pre-operatively. Two drops each of phenylephrine $10 \%$ and cyclopentolate $1 \%$ were administered one hour prior to surgery to obtain mydriasis.

Sixty-three of the operations were performed under general anaesthesia and twenty-five were performed with retrobulbar anaesthesia. Intra-operatively, 0.05-0.15 millilitres of aqueous humour were withdrawn with a tuberculin syringe through a 25 gauge needle after a partial thickness corneoscleral incision had been made but before the anterior chamber had been entered. The time interval between the topical administration of prednisolone acetate $(1.0 \%)$ or fluorometholone alcohol $(0.1 \%)$ and the aspiration of aqueous humour was recorded. The samples of aqueous humour were immediately frozen and stored at $-20^{\circ} \mathrm{C}$ until analysed by GCMS.

\section{Group 1 Aqueous Humour Samples}

Two nanograms of deuterated prednisolone (containing largely the tri-deuterated derivative $)^{4,5}$ were added to each sample of aqueous humour which had previously been diluted to one millilitre with high purity water. The aqueous layer was extracted with ethyl acetate $(2 \times 1 \mathrm{ml})$ and the extract was chemically treated to give the mono-methoxime di-trimethylsilyl ether derivative. ${ }^{4,5}$ the derivatised extract was then subjected to GCMS in the negative chemical ionisation mode; the undeuterated corticosteroid present in the aqueous humour was identified and quantified with reference to the known amount of ditrideuterated compound which had been added à an internal standard before extraction.

\section{Group 2 Aqueous Humour Samples}

One nanogram of dihydroxyprogesterone (DHP $1 \mathrm{ng}$ ) was added to each aqueous humour sample which had been diluted to one millilitre with high purity water. The aqueous layer was extracted with ethyl acetate $(2 \times 1 \mathrm{ml})$ and the extract was chemically derivatised to yield di-pentafluorobenzyloxime di-trimethylsilyl ether derivatives and then analysed by GCMS in the negative ion chemical ionisation mode. The undeuterated fluorometholone present in the aqueous humour was identified and quantified with reference to the known amount of deuterated DHP added as an internal standard. (DHP is a suitable internal standard because of the similarity of its mass spectrum to that of fluorometholone).

These deuterated internal standards for prednisolone and fluorometholone co-chromatographed with the corresponding undeuterated steroids and yielded characteristic ions in their mass spectra equivalent to those obtained from the undeuterated compounds together with a corresponding mass increment of 2-3 atomic mass units. This technique is suitable for the quantification of fluorometholone and prednisolone in concentrations as low as the $0.1-10 \mathrm{ng} / \mathrm{ml}$ range.

\section{Results}

The concentrations of prednisolone in human aqueous humour at varied time intervals following the topical administration of prednisolone acetate $1.0 \%$ are shown in Table I. The highest mean concentration $(669.6 \mathrm{ng} / \mathrm{ml})$ was found in the time interval 91-120 minutes, after the administration of the steroid. Subsequently the intraocular concentrations of the drug diminished. Significant concentrations of the drug were present at 12 hours and concentrations which were $5 \%$ of the peak level were measured at 24 hours. The concentrations of prednisolone found in aqueous humour are depicted in Fig. 1.

The fluorometholone concentrations in aqueous humour determined in our preliminary study of 22 samples are shown for progressive time intervals in Table II. (The full results for fluorometholone concentrations in aqueous humour, i.e. 50-60 samples, will be submitted for publication on completion of this project). The mean peak concentrations of the three ophthalmic steroids we have previously studied are compared with the corre- 
Table I Mean concentration $(\mathrm{ng} / \mathrm{ml})(+/-$ standard error of mean) of prednisolone in human aqueous humour at various times (min) following the topical administration of 50 microlitres of prednisolone acetate $(1.0 \%)$.

\begin{tabular}{|c|c|c|c|c|}
\hline \multirow{2}{*}{$\begin{array}{l}\text { Time } \\
\text { Interval } \\
\text { (Mins) }\end{array}$} & \multirow{2}{*}{$\begin{array}{l}\text { No of eyes } \\
\quad(n=66)\end{array}$} & \multicolumn{3}{|c|}{$\begin{array}{c}\text { Mean Concentration in } \\
\text { Aqueous Humour }\end{array}$} \\
\hline & & $(n g / m L)$ & $+1-$ & $(S E M)$ \\
\hline $0-\quad 30$ & 6 & 49.6 & $+1-$ & 14.4 \\
\hline $31-\quad 60$ & 10 & 171.4 & $+1-$ & 32.3 \\
\hline $61-\quad 90$ & 3 & 301.9 & $+1-$ & 87.3 \\
\hline $91-120$ & 6 & 669.6 & $+1-$ & 135.5 \\
\hline $121-180$ & 5 & 659.9 & $+1-$ & 94.9 \\
\hline $181-240$ & 6 & 453.0 & $+1-$ & 94.6 \\
\hline $241-360$ & 8 & 251.5 & $+1-$ & 26.1 \\
\hline $361-720$ & 6 & 132.9 & $+1-$ & 49.1 \\
\hline $721-1080$ & 5 & 99.5 & $+1-$ & 65.0 \\
\hline $1081-1320$ & 11 & 28.4 & $+1-$ & 9.9 \\
\hline
\end{tabular}

sponding parameter for prednisolone acetate in Table III.

There were no statistical differences in the steroid concentrations in aqueous humour when the results from patients receiving general anaesthetic were compared to those from patients who received retrobulbar anaesthetic.

\section{Discussion}

Most previous studies of the intraocular penetration of topically applied synthetic corticosteroids have used animal models and indirect radioimmunoassay techniques have usually been employed (see Ref. 2 for discussion). By employing GCMS in this study we have been able to measure the concentrations of steroid

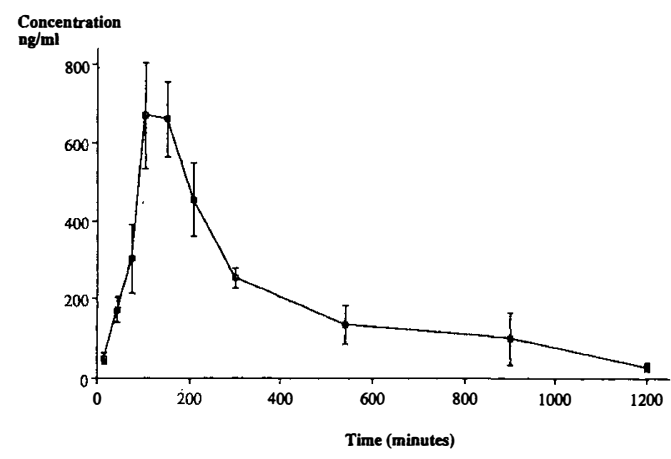

Fig. 1. Concentrations of prednisolone (ng/ml +1 - SEM) in aqueous humour vs time ( $\mathrm{min}$ ) following the topical instillation of prednisolone acetate $(1.0 \%)$. in human aqueous humour directly: rather than by the less specific method of measuring a radiolabelled fraction which is not able to distinguish between the steroid per se and its metabolites. GCMS is very specific in distinguishing intact steroids from metabolites and sensitive in the measurement of corticosteroids in the $0.1-10 \mathrm{ng} / \mathrm{ml}$ range. ${ }^{4,5}$

Animal studies have demonstrated a superior intraocular penetration of preparations of prednisolone acetate $(1.0 \%)$, and dexamethasone alcohol $(0.1 \%)$ when compared with other topical steroid preparations. ${ }^{6,7}$ Of the steroids we have analysed prednisolone acetate (1\%) afforded the highest mean peak concentration $(669.9 \mathrm{ng} / \mathrm{ml})$ in aqueous humour with peak levels more than twenty-fold greater than those of dexamethasone alcohol $(0.1 \%)(31.0 \mathrm{ng} / \mathrm{ml})$ and prednisolone sodium phosphate $(0.5 \%)$ $(25.6 \mathrm{ng} / \mathrm{ml})$. These differences may be explained partly by the higher $1.0 \%$ concentration of prednisolone acetate when compared to the lower concentrations of the other two steroids. ${ }^{8,9}$ Lipophilic acetate and alcohol corticosteroid preparations also penetrate the intact corneal epithelium better than polar (i.e. ionic) preparations such as sodium salts of the steroid phosphate $;^{10,11,12}$ hence, greater peak levels of dexamethasone despite the concentration $(0.1 \%)$ being one fifth that of prednisolone sodium phosphate $(0.5 \%)$. However, the difference between the absorption of the first two lipophilic preparations cannot be explained entirely in terms of differences in preparation concentration. It has been documented that the formulation of

Table II Mean concentration (ng/ml) (+l- standard error of mean) of fluorometholone in human aqueous humour at various times ( $\mathrm{min}$ ) following the topical administration of 50 microlitres of fluorometholone alcohol $(0.1 \%)$.

\begin{tabular}{lcccc}
\hline \multirow{2}{*}{$\begin{array}{l}\text { Time } \\
\text { Interval } \\
(\text { Mins })\end{array}$} & $\begin{array}{c}\text { No of eyes } \\
(n=22)\end{array}$ & \multicolumn{3}{c}{$\begin{array}{c}\text { Mean Concentration in } \\
\text { Aqueous Humour }\end{array}$} \\
\cline { 3 - 5 } & & $(n g / m L)$ & $+/-$ & $(S E M)$ \\
\hline $0-30$ & 4 & 1.92 & $+/-$ & 0.96 \\
$31-60$ & 2 & 5.1 & $+/-$ & 2.60 \\
$61-90$ & 8 & 4.25 & $+/-$ & 0.82 \\
$91-120$ & 3 & 2.6 & $+/-$ & 0.45 \\
$121-180$ & 3 & 4.03 & $+/-$ & 0.92 \\
$181-240$ & 2 & 4.3 & $+/-$ & 2.26 \\
\hline
\end{tabular}


Table III Comparison of the mean peak concentrations ( $\mathrm{ng} / \mathrm{ml}+/-$ standard error of mean) of steroid in human aqueous humour following the separate topical administration of 50 microlitres of prednisolone acetate $1.0 \% \quad(n=6)$, dexamethasone alcohol $0.1 \%(n=9)$, betamethasone sodium phosphate $0.1 \% \quad(n=10)$ or prednisolone sodium phosphate $(n=10)$.

Relative Mean Peak Concentrations $(\mathrm{ng} / \mathrm{ml})$ in Aqueous Humour

\begin{tabular}{lc}
\hline $\begin{array}{l}\text { Prednisolone } \\
\text { Acetate 1\%) }\end{array}$ & $669.6+/-(135.5)$ \\
$\begin{array}{l}\text { Dexamethasone } \\
\quad(\text { Alcohol 0.1\%) }\end{array}$ & $31.0+/-\quad(3.9)$ \\
$\begin{array}{l}\text { Prednisolone } \\
\quad \text { (Sodium Phosphate } 0.5 \%)\end{array}$ & $25.6+/-\quad(4.0)$ \\
$\begin{array}{l}\text { Betamethasone } \\
\quad \text { (Sodium Phosphate 0.1\%) }\end{array}$ & $7.7+/-\quad(1.8)$ \\
\hline
\end{tabular}

drugs (particularly vehicle and preservative) can significantly influence the penetration of topically applied steroids. ${ }^{10,12}$ In comparison to dexamethasone alcohol $(0.1 \%)$, prednisolone sodium phosphate $(0.5 \%)$ and betamethasone sodium phosphate $(0.1 \%)$ the preliminary results for fluorometholone $(0.1 \%)$ demonstrate a low mean peak concentration in aqueous humour $(5.1 \mathrm{ng} / \mathrm{ml})$ which is lower than our lowest previously recorded mean peak of $7.7 \mathrm{ng} / \mathrm{ml}$ for betamethasone sodium phosphate $(0.1 \%){ }^{3}$ However, when the absorption characteristics of these five steroids are compared it is important to remember that betamethasone and dexamethasone have an inherent systemic anti-inflammatory potency which is 5-7 times greater than that of prednisolone: ${ }^{14,15}$ However, it has been suggested that these systemic differences in potency cannot be extrapolated directly to the eye and thus it cannot be ruled out that these steroids behave differently in the intraocular milieu. ${ }^{6}$ If one accepts these differences in potency (with some reservation until they have been confirmed experimentally), then the appropriately adjusted indices of concentration (assuming a seven fold difference of potency between prednisolone and the other two steroids) in aqueous humour would be: prednisolone acetate 95.7, dexamethasone alcohol 31.0, betamethasone sodium phosphate 7.7 , and prednisolone sodium phosphate 3.7. Such standardised data are perhaps in accord with the perceived clinical potency of these respective preparations.
Concentrations of fluorometholone in aqueous humour at 10 hours post instillation have yet to be established but it is notable that significant levels of prednisolone (132.9 ng/ $\mathrm{ml})$ were present 10 hours after the instillation of prednisolone acetate $(1 \%)$, indeed, a concentration $(28.4 \mathrm{ng} / \mathrm{ml})$ greater than the mean peak concentration $(25.6 \mathrm{ng} / \mathrm{ml})$ attained by prednisolone sodium phosphate is found almost 24 hours after the application of the acetate preparation of the drug. Our previous results have shown that no aqueous humour concentrations of prednisolone could be recorded 10 hours after topical application of prednisolone sodium phosphate $(0.5 \%)$; in contrast, significant concentrations of dexamethasone (ca. $10 \%$ of peak levels) and betamethasone (ca. $32 \%$ of peak levels) are detected 10 hours after the instillation of dexamethasone alcohol $(0.1 \%)$ and betamethasone sodium phosphate $(0.1 \%)$ respectively.

The Authors believe this is the first comprehensive investigation of the penetration of commercially available topical corticosteroids into human aqueous humour. Our results confirm data obtained from animal model studies which suggest that prednisolone acetate $(1 \%)$ penetrates through the cornea in significantly greater quantities than the other ophthalmic preparations analysed. ${ }^{6}$ Our preliminary results for fluorometholone show that it reached the lowest peak concentration in aqueous humour of any of the five steroid preparations studied so far. However, further data on its pharmacokinetics in aqueous humour are required before meaningful final comparisons can be made. Moreover the contribution, if any, of these low levels to the known lower intraocular pressure response to this steroid remains to be elucidated. ${ }^{7,16,17}$ Prednisolone sodium phosphate (0.5\%) achieved peak concentrations within 91120 mins but was not detectable at 10 hours. $^{2}$ In contrast prednisolone acetate $(1.0 \%)$, betamethasone sodium phosphate $(0.1 \%)^{3}$ and dexamethasone alcohol $(0.1 \%)^{1}$ were all detectable in aqueous humour at eighteen hours. However, further data concerning intraocular concentrations attained following repeated topical doses is required, and clinical evaluation of the appropriately modified regimens is needed before alterations to regimens 
are postulated on the basis of these results. This paper forms part of a larger project to examine the pharmacokinetics of the commonly used, commercially available ophthalmic corticosteroid preparations and it is hoped that the results obtained might help to rationalise the dosage regimens of these drugs.

We thank: Miss Catherine Bates for technical assistance, Drs. Doig, Williamson, Kyle, Wykes, and Dudgeon for collecting aqueous samples, Glaxo Group Research Ltd, Merck Sharpe and Dohme Ltd, Alcon Ltd and Allergan (UK) Ltd for gifts of synthetic corticosteroids, The Scottish Hospital Endowment and Research Trust and the Scottish Home and Health Department for providing funding for the research.

\section{PROPRIETARY STATEMENT}

None of the authors has any commercial or proprietary interests in any of the steroid preparations mentioned nor any other topical ophthalmic corticosteroid eyedrops.

\section{References}

${ }^{1}$ Watson DG, Noble MJ, Dutton GN, Midgley JM, Healy TM: Penetration of topically applied dexamethasone alcohol into human aqueous humour. Arch Ophthalmol 1988, 106: 686-7.

${ }^{2}$ McGhee CNJ, Noble MJ, Watson DG, et al: Penetration of topically applied prednisolone sodium phosphate into human aqueous humour. Eye 1989, 3: 463-7.

${ }^{3}$ Watson DG, McGhee CNJ, Midgley JM, Noble MJ, Dutton GN: Penetration of topically applied betamethasone sodium phosphate into human aqueous humour. (Submitted to Eye).

${ }^{4}$ Midgley JM, Watson DG, Healey T, Noble MJ: The quantification of synthetic corticosteroids using isotope dilution gas chromatography negative chemical ionization mass spectrometry. Biomed and Environ Mass Spect 1988, 15: 479-83.

${ }^{5}$ Watson DG, Midgley JM, McGhee CNJ: The analysis of corticosteroid acetates by gas chromatography/negative ion chemical mass spectrometry. Rapid Communications in Mass Spect. 1989, 1: 8-10.
${ }^{6}$ Leibowitz HM and Kupferman A: Bioavailability and therapeutic effectiveness of topically administered corticosteroids. Trans Am. Acad Ophthalmol Otolaryngol 1975, 79: 78-87.

${ }^{7}$ Yamauchi H, Kito H, Uda K: Studies on intraocular penetration and metabolism of fluorometholone in rabbits: A comparison between dexamethasone and methasone and prednisolone acetate. Jap J. Ophthalmol 1975, 9: 339-47.

${ }^{8}$ Kupferman A and Leibowitz HM. Topically applied steroids in corneal disease. V1. Kinetics of prednisolone sodium phosphate. Arch Ophthalmol 1974, 92: 331-4.

${ }^{9}$ Leibowitz HM and Kupferman A: Kinetics of topically administered prednisolone acetate: Optimal concentration for the treatment of inflammatory keratitis. Arch Ophthalmol 1976, 94: 1387-9.

${ }^{10}$ Hull DS, Hine JE, Edelhauser, Hyndiuk RA: Permeability of the isolated rabbit cornea to corticosteroids. Invest Ophthalmol 1974, 13: 457-9.

${ }^{11}$ Flint GR and Morton DJ: Effect of derivatization on the bioavailability of ophthalmic steroids: Development of an in vitro method of evaluation. Arch Ophthalmol 1984, 102: 1808-9.

${ }^{12}$ Kupferman A, Pratt MV, Suckewer K, Leibowitz HM: Topically applied steroids in corneal disease: 111 , The role of drug derivative in stromal absorption of dexamethasone. Arch Ophthalmol 1974, 91: 373-6.

${ }^{13}$ Green $\mathrm{K}$ and Downs SJ: Prednisolone phosphate penetration into and through the cornea. Invest Ophthalmol 1974, 13: 316-8.

${ }^{14}$ Havener WH: Corticosteroid Therapy; in Ocular Pharmacology (Fifth Edition) Ed. William $\mathrm{H}$. Havener; CV Mosby Co, St Louis 1983: 433-500.

${ }^{15}$ Haynes RC and Murad F. in Goodman and Gilman's: The Pharmacological basis of therapeutics (Seventh Edition) Eds Goodman LS, Gilman AG; MacMillan Publishing Co, New York, 1985: $1475-7$

${ }^{16}$ Mindel JS, Tavitian HO, Smith H, Walker EC: Comparative ocular pressure elevation by medrysone, fluorometholone and dexamethasone phosphate. Arch Ophthalmol 1980, 98: 1577-8.

${ }^{17}$ Morrison E and Archer DB: Effect of fluorometholone (FML) on the intraocular pressure of corticosteroid responders. $\mathrm{Br} J$ Ophthalmol 1984, 68: 581-4. 